\title{
PATTERN OF ROAD TRAFFIC INJURIES IN LUBLIN COUNTY, POLAND
}

\author{
Mariusz Goniewicz' ${ }^{1}$ Adam Nogalski², Meleckidzedeck Khayesi ${ }^{3}$, Tomasz Lübek², Beata Zuchora², Krzysztof \\ Goniewicz', Paulina Miśkiewicz ${ }^{4}$ \\ ${ }^{1}$ Emergency Medicine Unit, Medical University of Lublin, Poland \\ ${ }^{2}$ Department of Trauma Surgery and Emergency Medicine, Medical University of Lublin, Poland \\ ${ }^{3}$ Department of Injuries and Violence Prevention and Disability, World Health Organization, Geneva, Switzerland \\ ${ }^{4}$ World Health Organization, Country Office in Poland, Warsaw, Poland
}

\begin{abstract}
SUMMARY
Background: Road traffic injury patients admitted to 35 hospitals in Lublin region.

Objective: To describe the pattern of road traffic injuries in Lublin county, Poland.

Methods: Review of medical records for the period from January 2004 to December 2005.

Results: Pedestrians accounted for the largest share of the Road traffic crash (RTC) injury cases (35.8\%) and $46.4 \%$ of deaths. The highest mortality was observed in motorcycle occupants $(7.1 \%)$ and victims with abdominal injuries $(9.8 \%)$. Vulnerable road users represented $71.4 \%$ of all RTC deaths, with mortality $5.8 \%$. Early transfers accounted for $82.5 \%$ of cases. Mortality in early transfers is 4 times higher than in late transfers.

Conclusions: Poland ranks as one of the worst European countries in terms of severity and fatal outcomes of road traffic injuries. Groups of road users in Poland at the highest risk are pedestrians, cyclists, children and young male drivers. The highest mortality rate occurs among road users affected by multiple trauma and head/vertebral column injuries. Alleviation of consequences of road traffic injuries in Poland may be achieved by coordinated efforts and collective responsibility of government, central level agencies, rescue team members and community groups.
\end{abstract}

Key words: road accidents, injuries

Address for correspondence: M. Goniewicz. Emergency Medicine Unit, Medical University of Lublin, Chodzki 6, 20-093 Lublin, Poland. E-mail: mariusz.goniewicz@gmail.com

\section{INTRODUCTION}

There is growing research on the pattern and structure of road traffic injuries at the international level. For instance, analysis of the magnitude, risk factors and interventions for road traffic injuries at the global level is evident in recent publications (1) continuing with some of the issues that had been identified in earlier studies $(2,3)$. About 5,500 people die and 65,000 others are injured and disabled each year in Poland due to road traffic injuries (4). Eleven people die in every 100 road traffic crashes in Poland, compared to 3 fatalities per 100 road traffic collisions for Western European Countries $(5,6)$. Though an analysis of road traffic injuries at the global and national levels is necessary, there is a need for a sub-national level analysis to provide evidence for policy makers and provide background for prevention programmes. This article examines the pattern and structure of road traffic injuries in Lublin county, Poland. This county is located in the Southeastern part of Poland, with an area of 25 $155 \mathrm{~km}^{2}$ and a population of 2,250,000 people, of whom $46.5 \%$ live in urban areas.

\section{MATERIALS AND METHODS}

A retrospective review of medical records of patients admitted with road traffic injury to all 35 hospitals in Lublin region during the period from January 2004 to December 2005 was conducted.

This paper deals with the first part of the research embracing the 2004-2013 period carried out under the auspices of the World Health Organization and analyses the road traffic injuries in county Lublin.

The records were obtained from information routinely transmitted from all hospitals to the Regional Public Health Centre. This is a Ministry of Health institution responsible for collecting information on all diseases in Lublin voivodship. All rural (26) and urban (9) hospitals in Lublin region routinely submit information to this centre. The information is recorded using ICD 10th revision. This system has been used in Poland since 1992 (7). In this study codes ST were used for injury type classification while VY codes were used for road users group identification. Interhospital transfers were extracted using personal identification number of each patient. We traced information on each patient for a period of 12 months. All records were examined and data extracted on demographic characteristics, type of injury, external cause of injury, type of road user. Details are shown in Table 1.

The data extracted were entered into a database developed using STATISTICA v. 6.0 (7). The data were edited, processed and analysed. Crosstabulation was performed and tests of significance conducted using $\chi^{2}$ test where applicable, with $95 \%$ confidence interval. The statistical significance was based on $\chi^{2}$ test and assumed for $\mathrm{p}<0.05$. 
Table 1. Specification and measurement of variables

\begin{tabular}{|l|l|}
\hline Variable & Measurement \\
\hline Age & Physical age indicated by number of years \\
\hline Sex & Male, female \\
\hline Anatomical site & Neck, head, chest, abdomen, extremities \\
\hline Injury outcome & $\begin{array}{l}\text { • Death (a fatality occurring within 30 days of the } \\
\text { crash) } \\
\text { - Injury (non-fatal, requiring hospital admission; } \\
\text { type of injury - fractures or concussions - } \\
\text { whether or not admitted }\end{array}$ \\
\hline Length of hospital stay & $\begin{array}{l}\text { Number of days each patient stayed in hospital, } \\
\text { from admission to discharge }\end{array}$ \\
\hline Road user & $\begin{array}{l}\text { Means of transport used by the patient at the } \\
\text { time of the crash: pedestrian, bicycle/moped } \\
\text { user, motorcycle user, car occupant, bus or truck } \\
\text { occupant, other }\end{array}$ \\
\hline
\end{tabular}

\section{RESULTS}

The results presented here are for 9,973 road traffic injury patients who were admitted and whose records were submitted to the Regional Public Health Centre during the period under study. There were 6,578 (66.0\%) males and 3,395 (34.0\%) females. The mean age, standard deviation and range of age: for the entire sample were 36.2, $+/-20.2$ and $0-99$; for males 35.2, $+/-19.2$ and 0-99; for females 38.1, +-21.9 and 0-94, respectively. Among 427 fatalities in analysed group there were 294 (68.9\%) males and $133(31.1 \%)$ females. Mortality in analysed population reached $4.3 \%$ and in males was significantly higher than in females $(4.5$ vs. $3.9 \%$ respectively, $\mathrm{p}<0.001$ ) (Table 2).

People aged from 16 to 30 years constituted the age group which contributed most significantly to the total number of road traffic crash (RTC) injuries registered (35.2\%); more than any other age group $(35.2 \%$ vs. $20.7 \%, \mathrm{p}<0.001)$.

Pedestrian accounted for the largest proportion of RTC injury cases $(35.8 \%)$, the highest recorded number in children and elderly people (39.5\% and $45.7 \%$ respectively), followed by car occupants $(28.3 \%$ of cases) with the highest percentage in age group ranging from 31 to 60 years of age ( 34.5 and 37.1 respectively). Pedestrians and bicycle/moped occupants together accounted for the largest share of RTC injury cases in children and elderly people age group ( 62.4 and $65.1 \%$ of all cases in these age groups respectively). Pedestrians accounted for $46.4 \%$ of all fatalities. The highest mortality was observed in motorcycle users (7.1\%) and this mortality is significantly higher than in any other road user group ( $7.1 \%$ vs $5.8 \%$, p $<0.001)$, followed by bicycle/moped users $(5.8 \%)$ and pedestrians (5.5\%) (Table 3$)$.

One forth of injured body region was head/neck injuries followed by lower and upper limbs injury. The biggest contribution to all deaths were accounted for head/neck related fatalities (31.4\%), but the highest mortality was observed in patients with abdominal region injuries $(9.8 \%)$, followed by multiple injuries $(8.1 \%)$, and spine injuries $(7.0 \%)$. The differences in observed mortality was significant ( 9.8 vs. $8.1, \mathrm{p}<0.001)$.

Different distribution of injuries localizations were indicated in different road users groups and differences are statistically significant $\mathrm{p}<0.001$. Similar distribution was observed only in spine injuries $(\mathrm{p}=0.87)$. For vulnerable road users multiple injuries followed by head/neck and lower limbs have had the biggest contribution to all injury while abdomen, chest, and external injuries were dominated in protected road users (Table 4).

In the analysed population $48.3 \%$ of patients had to be transferred to higher level health institutions after the crash. Early transfers are usually necessary in severe injured subjects as the province hospitals have limited possibilities for treatment of such injuries. It is worth to notice that $82.5 \%$ of all early transfers were vulnerable road users; the fact confirms observation of injury severity and higher mortality in this group of road users. Moreover, mortality observed in early transferred patients was four times higher than average mortality in analysed population of road traffic victims (12.1 vs. 4.3 respectively, $\mathrm{p}<0.001)$ as well as four times higher than mortality in late transfers (12.1 vs. 4.4, respectively, $\mathrm{p}<0.001$ ).

\section{DISCUSSION}

Intensive development of motor transport results in parallel increase in road traffic injuries and represents a major public

Table 2. Involvement of road users by age groups

\begin{tabular}{|c|c|c|c|c|c|c|c|c|}
\hline \multirow[t]{2}{*}{ Road user group } & \multicolumn{5}{|c|}{ Age groups } & \multirow{2}{*}{$\begin{array}{l}\text { Total no. ( } \% \\
\text { of all cases) }\end{array}$} & \multirow{2}{*}{$\begin{array}{l}\text { Deaths no. } \\
\text { (\% of all } \\
\text { deaths) }\end{array}$} & \multirow{2}{*}{$\begin{array}{c}\text { Mortality } \\
\%\end{array}$} \\
\hline & $0-15$ & $16-30$ & $31-46$ & $47-60$ & $>60$ & & & \\
\hline Pedestrian no. (\%) & $521(39.5)$ & $1,309(37.3)$ & $603(29.2)$ & $481(29.5)$ & $660(45.7)$ & $3,574(35.8)$ & $198(46.4)$ & 5.5 \\
\hline Bicycle no./moped (\%) & $302(22.9)$ & $266(7.6)$ & $44(2.1)$ & $53(3.3)$ & $281(19.4)$ & $946(9.5)$ & $55(12.9)$ & 5.8 \\
\hline Motorcycle occupant (\%) & $15(1.1)$ & $278(7.9)$ & $215(10.4)$ & $211(12.9)$ & $18(1.2)$ & $737(7.4)$ & $52(12.2)$ & 7.1 \\
\hline Car occupant (\%) & $214(16.2)$ & $740(21.1)$ & $714(34.5)$ & $604(37.1)$ & $239(16.5)$ & $2,511(28.3)$ & $108(25.3)$ & 4.3 \\
\hline Bus/truck occupant (\%) & $197(14.9)$ & $679(19.3)$ & $344(16.6)$ & $209(12.8)$ & $173(12.0)$ & $1,602(12.2)$ & $10(2.3)$ & 0.6 \\
\hline Others no. (\%) & $69(5.2)$ & $240(6.8)$ & $148(7.2)$ & $72(4.4)$ & $74(5.1)$ & $603(8.5)$ & $4(0.9)$ & 0.7 \\
\hline $\begin{array}{l}\text { Total no. } \\
\text { ( } \% \text { of age group) } \\
\text { ( } \% \text { of all cases) }\end{array}$ & $\begin{array}{l}1,318 \\
(100) \\
(13.2)\end{array}$ & $\begin{array}{l}3,512 \\
(100) \\
(35.2)\end{array}$ & $\begin{array}{l}2,068 \\
(100) \\
(20.7)\end{array}$ & $\begin{array}{l}1,630 \\
(100) \\
(16.3)\end{array}$ & $\begin{array}{l}1,445 \\
(100) \\
(14.5)\end{array}$ & $\begin{array}{l}9,973 \\
(100) \\
(100)\end{array}$ & $\begin{array}{l}427 \\
(100) \\
(4.3)\end{array}$ & 4.3 \\
\hline
\end{tabular}

* Mortality - percentage of deaths in total number of road user group 
Table 3. Type of injury by road user groups

\begin{tabular}{|l|c|c|c|c|c|c|}
\hline Type of injury & $\begin{array}{c}\text { Vulnerable road } \\
\text { users* no. (\%) }\end{array}$ & $\begin{array}{c}\text { Protected road } \\
\text { users** no. (\%) }\end{array}$ & $\begin{array}{c}\text { Vulnerable vs. } \\
\text { protected }\end{array}$ & $\begin{array}{c}\text { Total no. } \\
\text { (\% of all cases) }\end{array}$ & $\begin{array}{c}\text { Deaths no. } \\
\text { (\% of all deaths) }\end{array}$ & $\begin{array}{c}\text { Mortality }{ }^{* * *} \\
\%\end{array}$ \\
\hline Multiple & $570(66.5)$ & $287(33.5)$ & $p<0.001$ & $857(8.6)$ & $69(16.2)$ & 8.1 \\
\hline Head/neck & $1,512(60.4)$ & $990(39.6)$ & $p<0.001$ & $2,502(25.1)$ & $134(31.4)$ & 5.4 \\
\hline Chest & $382(42.1)$ & $526(57.9)$ & $p<0.001$ & $908(9.1)$ & $54(12.6)$ & 5.9 \\
\hline Abdomen & $319(39.4)$ & $491(60.6)$ & $p<0.001$ & $810(8.1)$ & $79(18.5)$ & 9.8 \\
\hline Spine & $297(49.7)$ & $301(50.3)$ & $p=0.87$ & $598(6.0)$ & $42(9.8)$ & 7.0 \\
\hline Upper limbs & $620(44.4)$ & $776(55.6)$ & $p<0.001$ & $1,396(14.0)$ & $9(2.1)$ & 0.6 \\
\hline Lower limbs & $1,037(60.1)$ & $688(39.9)$ & $p<0.001$ & $1,725(17.3)$ & $25(5.9)$ & 1.4 \\
\hline External & $520(44.2)$ & $657(55.8)$ & $p<0.001$ & $1,177(11.8)$ & $15(3.5)$ & 1.3 \\
\hline Total & $5,257(52.7)$ & $4,716(47,3)$ & $p<0.001$ & $9,973(100)$ & 427 & 4.3 \\
\hline
\end{tabular}

${ }^{*}$ Vulnerable road users - V01-V39, ${ }^{* *}$ Protected road users V40-V89, ${ }^{* * *}$ Mortality - percentage of deaths in total number of injury type.

Table 4. Interhospital transfers by road users group

\begin{tabular}{|l|c|c|c|c|c|}
\hline Transfers & $\begin{array}{c}\text { Vulnerable road users } \\
\text { no. (\%) }\end{array}$ & $\begin{array}{c}\text { Protected road users } \\
\text { no. (\%) }\end{array}$ & $\begin{array}{c}\text { Total no. (\% of all } \\
\text { cases) }\end{array}$ & $\begin{array}{c}\text { Deaths no. (\% of all } \\
\text { deaths) }\end{array}$ & $\begin{array}{c}\text { Mortality in variable } \\
\text { group (\%) }\end{array}$ \\
\hline Early transfers* $\mathrm{n}(\%)$ & $557(10.6)$ & $118(2.5)$ & $675(6.8)$ & 8219.2 & 12.1 \\
\hline Late transfers* & $2,181(41.5)$ & $963(20.4)$ & $3,144(31.5)$ & $137(32.1)$ & 4.4 \\
\hline Not transferred & $2,519(47,9)$ & $3,635(77.1)$ & $6,154(61.7)$ & $208(48.7)$ & 3.4 \\
\hline Total & $5,257(100)$ & $4,716(100)$ & $9,973(100)$ & $427(100)$ & 4.3 \\
\hline
\end{tabular}

* Patients transferred to another hospital within 24 hours after the crash.

** Patients transferred to another hospital between 2 nd and 30th day after the crash

health and social problem. Crude data estimate that every $50 \mathrm{sec}-$ onds unintentional road traffic injuries result in death worldwide and every 2 seconds many people are left permanently injured or disabled. Moreover, the death rate of seriously injured people constitutes $2.2 \%$ of all deaths globally. The related economic costs are enormous - road traffic injuries being already the leading cause of injury-related disability affect mainly young people within productive life span $(1,2,3)$.

Poland ranks as the one of the worst European countries in terms of road traffic safety level measured by number of road traffic accidents and their consequences. The number of fatalities resulting from road traffic injuries in Poland is 150 people per million inhabitants, whereas in the most safe countries as Sweden, Great Britain and Holland this rate is between 50 and 60 (8).

According to European Transport Safety Council database, the most tragic situation in respect of road traffic safety is in Greece (1,576 people killed per million inhabitants). Polish voivodships - Warmian-Masurian, Świętokrzyskie, Podlachian and Lublin rank on 4th, 12th, 15th and 16th positions with fatality numbers reaching $815,617,595$ and 590, respectively $(5,6)$.

The analysis of road traffic prevention in Poland highlights that the leading factor responsible for high number of fatalities on the roads is a sequel of disrespect for the rights of the most vulnerable road users - pedestrians and cyclists. Fatality rate among pedestrians in absence of obvious wrongdoing on their part reaches almost $60 \%$ in urban areas. The second key risk factor is violation of the speed limits by 75 and $54 \%$ of drivers within urban and rural areas, respectively. Next serious imminence of road traffic safety in Poland are the young drivers. Data routinely collected by Police indicate that $18 \%$ of road traffic collisions in Poland are caused by drivers between 18-25 years of age. Furthermore, the fatality rate of road traffic injuries caused by them constitutes $18 \%$ of all road traffic deaths. Young drivers represent $10 \%$ of the general Polish population. According to the report, the major risk factors that leads to increasing number of fatalities involving young drivers are lack of driving experience, the drink-driving, inclination to hazard behaviour on the roads and inability to adopt driving to respective road traffic conditions $(4,5)$.

Data obtained in this study demonstrate that the most vulnerable group of road users are people under 30 years of age. The results are conformable to data published by other authors indicating that road traffic injuries are leading factor of death in road users between 15-19 years of age. Road traffic injuries affecting the groups of road users aged between 10-14, 20-24 and 5-9 years is the second and third cause of death, respectively. The most vulnerable group are young males. World Health Organization (WHO) data highlight that every hour around 40 road traffic fatalities affects people under 25 years of age worldwide $(9,10)$.

Around $50 \%$ of road traffic fatalities occur in Africa and SouthEast Asia. The costs related to road traffic injuries are enormous. WHO reports demonstrate that economic cost of road traffic injuries in low-income and middle-income countries reaches 65-100 billion US \$ per year. Estimated annual cost of road crashes in Poland is about $2 \%$ of GNP (11-14).

Obtained results indicate that road traffic injuries in Poland disproportionately affect pedestrians, cyclists and motorcyclists. 
However, the most vulnerable groups among them are children, disabled persons and old people.

It is estimated that pedestrians are the most vulnerable group of road users - needless death or disability due to such traumas happen 10 times more often than among drivers. Moreover, a large proportion of childrens' deaths are unavoidable because of severity of their initial trauma. Among the remainder, especially old people, the appropriate care and rehabilitation for them create major economic and social problem. According to the published data, the chance of survival of pedestrians injured on or near zebra crossing depends on the vehicle's speed. It should be highlighted that limitation of speed from 60 to 50 $\mathrm{km} / \mathrm{h}$ may increase survival rate among pedestrian from 15 to $45 \%$ (15). Problem of pedestrians and cyclists vulnerability is known worldwide (16). Data collected by the Police indicate that number of injuries among pedestrians occurring each year in Poland on zebra crossing increased from $27 \%$ in 1998 to $29.8 \%$ in 2005. The police and in-hospital data vary, but the death and disability rates of injured pedestrians in Poland are enormously high $(17,18,19)$. It is estimated that every 24 minutes one of them is killed or seriously disabled. Road traffic accidents affecting pedestrians in Poland constitutes $40 \%$ of all traffic events, whereas in other EU countries only $8-19 \%$ of pedestrians are affected. The large proportion among injured pedestrians are children. Obtained results are conformable to data published by other authors indicating that young males under 15 years of age are the most vulnerable group of road users. Other reviews highlight that young males are even 2-4 times more vulnerable that females $(20,21)$.

The key factors of high vulnerability among children are inability of adequate assessment of road traffic situation, hazard spontaneous behaviour during games at not permissible places situated in the proximity of roads.

Safe road traffic participation of children depends on their psychomotor development and subsequent reaction of central nervous system (CNS) to external stimuli. However, not only the insufficient perceptiveness observed in young children, but also delay in decision making resulting from a lack of ability to analyse and synthesize observed events creates the major factor responsible for observed high vulnerability. In older children those abilities improve, although consecutive imminences, such as overestimation of driving possibilities and inclination to competition create alarming problem (22).

Obtained results indicate increasing number of multiple traumas among injured. A large proportion of victims died following severe head and neck injuries. The numbers and type of injuries as well as data about the circumstances in which those injuries occurred are comparable with the data given by other authors. About $60 \%$ of people affected by multiple trauma die at the scene of accident or in the minutes following injury. Remaining part of severely injured people requires adequate hospital care services because of coexisting hypovolemic shock, acute respiratory failure, CNS traumas $(23,24)$.

Our data indicate that head and extremities injuries are the leading health problems in road users with multiple trauma. In addition, Emergency Services in Poland usually transport the victim to the nearest hospital often without Emergency department and proper personnel and physical facilities to treat severe road traffic injuries.

\section{Limitations}

Although the proportion of road traffic accidents to the total number of vehicles in Poland is comparable with adequate ratio found in the other European countries, USA or Canada, the number of fatalities resulting from road traffic accidents in Poland is frightfully high. Majority of trauma deaths occur in the pre-hospital setting due to inadequate organisation of prehospital care system: time of receiving medical assistance at the scene of accident and transport of injured people to hospitals is too long. Moreover, lack of adequate number of Trauma Centers plays a key role in insufficient provision of appropriate care for injured people. It is commonly accepted that general strategy of the appropriate care of trauma patients should correspond with the principle presented in early sixties by D.D. Trunkeya "Right patient in the right time to the right hospital". In fact, our data indicate that mortality rate of trauma patients treated in non specialised regional hospitals was 4 times higher then in group admitted immediately to the centers ensuring appropriate trauma care for all injured. Establishment of interdisciplinary regional trauma care centers in USA and Germany significantly decreased mortality rate among victims of road traffic accidents by about $30-50$ and $25 \%$, respectively $(25,26,27)$.

Unfortunately, the report notes that there is still a long way to go - implementation of hospital care system based on regional trauma centers in Poland is only planned.

\section{CONCLUSION}

These findings indicate the road users groups for which especial prevention programme should be addressed.

Establishment of interdisciplinary regional trauma care center is an effective strategy to reduce road traffic related fatalities.

Number of early transfers could be a good indicator of Emergency services effectiveness and points to the necessity of regional trauma system organisation.

\section{Acknowledgements}

The authors would like to thank the World Health Organization Department of Injuries and Violence Prevention for their support in initiating the in-depth road crushes analysis in Poland, to the Regional Public Health Centre for sharing the injury related database of Lublin region, to the chiefs and personnel of the Lublin Police Headquarter for their contribution in road injury research.

\section{REFERENCES}

1. Peden M, Scurfield R, Sleet D, editors. World report on road traffic injury prevention. Geneva: WHO; 2004.

2. Peden M, McGee K, Krug E, editors. Injury: a leading cause of the global burden of disease. Geneva: WHO; 2002.

3. Murray CJL, Lopez AD, editors. The Global burden of disease: a comprehensive assessment of mortality and disability from diseases, injuries and risk factors in 1990 and projected to 2020. Boston: Harvard School of Public Health; 1996.

4. Polish Police Headquarters Road Traffic Accidents [Internet]. Warsaw: Polish National Police; 2011 [cited 2012 Apr 25]. Available from: http:// www.kgp.gov.pl. (In Polish.)

5. National Road Safety Council [Internet]. Warsaw: National Road Safety Council; 2011 [cited 2012 Apr 25]. Available from: http//www.krbrd.gov. pl. (In Polish.) 
6. European Transport Safety Council [Internet]. Brussels: European Transport Safety Council [cited 2012 Apr 25]. Available from: http://www.etsc. eu.

7. World Health Oraganization. International statistical classification of diseases and health related problems - 10th revision. Geneva: WHO; 1992.

8. Krystek R. Road safety in Poland, myths and reality. Gdansk: Global Road Safety Partnership; 2003.

9. Nantulya VM, Reich MR. The neglected epidemic: road traffic injuries in developing countries. BMJ. 2002 May 11;324(7346):1139-41.

10. Langley JD. Experiences using New Zealand's hospital based surveillance system for injury prevention research. Methods Inf Med. 1995 Sep;34(4):340-4.

11. Mohan D. Road traffic injuries-a neglected pandemic. Bull World Health Organ. 2003;81(9):684-5.

12. World Health Organization. A 5-year WHO strategy for road traffic injury prevention. Geneva: WHO; 2001.

13. Odero W, Garner P, Zwi A. Road traffic injuries in developing countries: a comprehensive review of epidemiological studies. Trop Med Int Health. 1997 May;2(5):445-60.

14. Mock CN, nii-Amon-Kotei D, Maier RV. Low utilization of formal medical services by injured persons in a developing nation: health service data underestimate the importance of trauma. J Trauma. 1997 Mar;42(3):50411; discussion 511-3.

15. Retting RA, Ferguson SA, McCartt AT. A review of evidence-based traffic engineering measures designed to reduce pedestrian-motor vehicle crashes. Am J Public Health. 2003 Sep;93(9):1456-63.

16. Mayou R, Bryant B. Consequences of road traffic accidents for different types of road user. Injury. 2003 Mar;34(3):197-202.

17. Cryer PC, Westrup S, Cook AC, Ashwell V, Bridger P, Clarke C. Investigation of bias after data linkage of hospital admissions data to police road traffic crash reports. Inj Prev. 2001 Sep;7(3):234-41.
18. Langley J, Stephenson S, Cryer C, Borman B. Traps for the unwary in estimating person based injury incidence using hospital discharge data. Inj Prev. 2002 Dec;8(4):332-7.

19. Razzak JA, Laflamme L. Limitations of secondary data sets for road traffic injury epidemiology: a study from Karachi, Pakistan. Prehosp Emerg Care. 2005 Jul-Sep;9(3):355-60.

20. Híjar M, Trostle J, Bronfman M. Pedestrian injuries in Mexico: a multimethod approach. Soc Sci Med. 2003 Dec;57(11):2149-59.

21. Ganveer GB, Tiwari RR. Injury pattern among non-fatal road traffic accident cases: a cross-sectional study in Central India. Indian J Med Sci. 2005 Jan;59(1):9-12.

22. Dhillon PK, Lightstone AS, Peek-Asa C, Kraus JF. Assessment of hospital and police ascertainment of automobile versus childhood pedestrian and bicyclist collisions. Accid Anal Prev. 2001 Jul;33(4):529-37.

23. Stella J, Sprivulis P, Cooke C. Head injury-related road crash mortality in rural Western Australia. ANZ J Surg. 2001 Nov;71(11):665-8.

24. Mackay GM, Cheng L, Smith M, Parkin S. Restrained front seat car occupant fatalities-the nature and circumstances of their injuries. Accid Anal Prev. 1992 Jun;24(3):307-15.

25. Rutledge R. The goals, development, and use of trauma registries and trauma data sources in decision making in injury. Surg Clin North Am. 1995 Apr;75(2):305-26.

26. Esposito TJ, Sanddal ND, Hansen JD, Reynolds S. Analysis of preventable trauma deaths and inappropriate trauma care in a rural state. J Trauma. 1995 Nov;39(5):955-62.

27. Nathens AB, Brunet FP, Maier RV. Development of trauma systems and effect on outcomes after injury. Lancet. 2004 May 29;363(9423):1794801. Erratum in: Lancet. 2005 Nov 19;366(9499):1772.

Received November 23, 2011 Accepted in revised form March 16, 2012 